\title{
The effect of sub-climatic characteristics on urban behavior patterns based on two case studies: Yazd (hot and arid climate) and Fooman (moderate and humid climate) urban spaces
}

Sara Ahmadi ( $\sim$ sara.ahmadi84@gmail.com )

Tehran University of Art

Hossein Bahrainy

Tehran University

\section{Short Report}

Keywords: Climate, Behavioral Patterns, Fooman, Urban Spaces, Yazd

Posted Date: November 23rd, 2021

DOI: https://doi.org/10.21203/rs.3.rs-1104403/v1

License: (a) This work is licensed under a Creative Commons Attribution 4.0 International License.

Read Full License 


\section{Abstract}

Severe climatic conditions are considered as one of the main factors shaping and in some cases limiting urban behaviors. Accordingly, environmental designers seek to make urban spaces usable for a wide range of behaviors during different times by bringing sub-climates closer to the comfort zone. The present study aims to evaluate the effects of sub-climate on behavioral patterns and explore solutions to moderate harsh climatic conditions in architecture and urban planning. This study compared the behavioral patterns of space users in hot and arid (Yazd) and moderate and humid (Fooman) climates. The recording of behavioral patterns was achieved by using the observation method (time-lapse photography) and analysis through the spatial analysis method. Based on the results, climatic characteristics affect both types of urban activities and the time cycles of their occurrence. Severe climatic conditions limit urban behaviors to essential activities and merely transcend space. Such states do not allow for a wide range of optional and social activities. Spatial physical tools such as building density, enclosure, occupancy level, amount of retreat on the ground floor and upper floors, type of building material, and the amount of green space have been used in historical formal-spatial patterns of Iran to moderate the harsh climatic conditions.

\section{Introduction}

In the contemporary era, human presence and behavior in urban spaces have become so crucial that many experts consider it as "the turn to deal with urban space and what is happening " ((Soja, 2010). The importance of behaviors in urban spaces can be discussed in many different ways. In contemporary urban design literature, the importance of urban behaviors is discussed in terms of their impact on cultural aspects (such as cultural identity, collective consumption, lifestyle (Castells, 1977; 1983; Soja, 1971)), social elements (such as interactions, public consensus, building trust, strengthening social capital, social justice, etc. (Bereitschaft, 2017; Halbwachs, 2020; Askarizad \& Safari, 2020), economic aspects (Harvey, 2000), environmental aspects (Hamin \& Gurran, 2009), and aspects of health (Direito et al., 2018; Koohsari et al., 2018; McCormack et al., 2019). Regarding health, recent research has shown that the rate of walking in urban areas plays a significant effect on lowering blood pressure (Li et al., 2009), reducing anxiety (Kelly et al., 2007), preventing osteoporosis (Rohrer et al., 2004), reducing type 2 diabetes (De Greef et al., 2011; Taylor et al., 2008) decreasing body mass index (Frank et al., 2006; Smith et al., 2008) and overall physical (Kelly et al., 2007), and mental health (Leventhal \& Brooks-Gunn, 2003).

Therefore, there are few contemporary urban design movements that have disregarded the need to increase, intensify, giving quality, and diversify the range of urban behaviors among citizens. Climatic characteristics are considered as one of the guiding, directing, shaping and, limiting factors of behaviors in urban spaces. Accordingly, the climatic requirements of different climates and their corresponding physical-spatial principles should be identified for diversifying and deepening urban behaviors, which can bring the sub-climates of urban spaces closer to the human comfort zone. In addition, climatic typology, as the study of those formal and spatial patterns which have stood the test of time for climatic features for hundreds of years, is a good inspiration source. 


\section{Conceptual framework of the study}

\section{Environment as a limiting factor}

Regulating the world of living organisms is considered as one of the main functions of the environment (natural and artificial) (Rapoport, 1976). For millions of years, the natural environment has imposed its physical requirements on the way of life among living things. Further, organisms have adopted two main approaches for survival including adaptation to the environment and changing the environment (Rapoport, 1976). Surviving different organisms only by adapting to environmental characteristics is considered as the fundamental difference between humans and other organisms on Earth. However, man changes the environment for the purpose of reducing its imposed order in a dialectical relationship, which gives him more freedom of action or autonomy. In other words, the psychological need for "autonomy" (Deci \& Ryan, 1991) is one of the main objectives in transforming the "natural environment" into a "human-built space" (Cowan \& Rogers, 2005). Based on a dialectical approach, man is simultaneously is influenced and influenced by the environment, which is known in anthropology as an organic approach (Reeve et al., 2004). In addition, adverse climatic condition is one of the aspects by which humans have tried hard to mitigate. It is easily be claimed that the creation of climatic comfort is easily found in significant human interventions or as the major architectural and urban works of world history (Rapoport, 2013).

\section{Environment and behavioral patterns}

In terms of behavior, the environment and space may be deterrent or restrictive, or maybe "supportive (or encouraging)" (Alfonzo et al., 2008; Cervero et al., 2009; Koo et al., 2021; Hahm et al., 2019). Today, there is almost no consensus that the environment can determine the "possibility" or "probability" of a behavior occurring (Philo, 2009). In the environment design literature, the first approach is known as "possibilistic", and the second is "probabilistic". In both approaches, the environment determines the time or time cycles, type, and communication, and audience of the behavior.

Regarding the time dimension, space depends on whether the behavior occurs in the "longitudinal transition[1]" or the "rotational transition" (Lynch, 1972; Rapoport, 2013), the value of time (the degree of accuracy in dividing behaviors into smaller time units) (Simmel, 2012) and how often the period of rotational behaviors are repeated with frequency, and finally, how far the behavior is from the origin, where the distance from the beginning of the solar year contracts to the beginning of the day, is effective. For example, in analyzing the behavior of Copenhagen citizens, Gehl and Gemzoe (1999) found that the number of users of urban spaces doubled in summer, the number of times they spent in these spaces increased fourfold, and their density increased eightfold in winter.

As for the type of behavior, environments influence whether the significant behaviors performed in space are necessary or optional, or social (Gehl, 1980). The environment influences whether behaviors are recreational or purposeful (Kwon \& Silva, 2020) or whether space is used only for passing or encouraging people to attend (Whyte, 1980). Most importantly, environments influence whether the behavior is 
avoidance or spontaneous (Reeve, 2014). These categories are more important than anything else regarding the impact that different types of behavior have on mental health. Avoidance behaviors are designed to address deficiencies, stresses, and environmental anxieties, which do not lead to eudemonia at all, but will only result in relief (Ryan \& Deci, 2000). In the opposite direction, self-determined behaviors are not based on environmental requirements, while satisfying basic psychological needs such as increasing autonomy and improving performance, happiness, good mood regarding an autonomous basis, and the individual's inner desires, leading to mental health (Reeve, 2014). In this regard, Gehl and Gemzoe (1999) observed that the people of Copenhagen take long and fast steps in winter, while they walk more slowly and have a high level of recreation in summer. In other words, people try to avoid bad environmental conditions in winter, while they have more autonomy in choosing behavior in summer. A person's motivation to perform a behavior is important in explaining the type of behavior. Accordingly, there is a little difference in appearance between some behaviors such as purposeful (walking trips with predetermined destinations) and recreational walking (walking with a wanderer) (Kwon \& Silva, 2020) due to cultural factors. However, they are fundamentally different from each other in terms of content, although the method of conventional contemporary research is exempt from explaining their differences. Regarding the dimension of communication, the environment influences who, where, and which field a person communicates (Rapoport, 2016). On the other hand, they express and control the nature, density, volume, and direction of communication simultaneously (Rapoport, 2016). In addition, environments affect the continuity of communication, social interaction, depth of relationships, and the like (Becker \& Steele, 1995; Fleming \& Singer, 1985; Moos, 1973; Peponis et al., 2002; Sundstrom et al., 1986). Further, the environment determines that only one specific social group or, in contrast, all social groups are allowed to use space (Boakye-Dankwa et al., 2019; Sun et al., 2020). Some environments such as ghettos, communes, and colonies approach the concept of the congregation only to allow individual and necessary interactions with familiar people such as the study of Wirth from the Jewish community in America (Wirth, 1998) or the study of Gans in an Italian immigrant living in West and Boston (Gans, 1962). However, other environments allow for impersonal and optional interactions with strangers as they approach the concept of community or vibrant urban space as portrayed by Jacobs (1961) and Tonkiss (2005).

Now, after examining the limitations that space (here urban space) can impose in time, communication, and type of behavior (urban behavior in this study), it is necessary to focus on which space with which amount of "liberation" and "autonomy" are strongly influenced by the political-cultural approach and framework of the decision-making system such as in the liberal-democratic direction. According to Habermas and Habermas (1971), a democratic system is the existence of an independent public sphere in which free social actions (discursive interaction) take place to achieve consensus (Habermas \& Habermas, 1971). In other words, a precondition for a democratic system is a high degree of autonomy in all spheres. Regarding public spaces including urban areas, Rapoport (2016) argues that instead of facilitating movement and access, the limitation of the Islamic system is intended to control behaviors. However, by adopting a liberal-democratic approach, those urban spaces are desirable, which allows a 
wide range of urban behaviors to occur in a wide range of areas. Accordingly, people can choose the desired behavior based on their inner desires.

In addition, unfavorable climatic conditions are regarded as one of the limiting factors of urban behaviors. As mentioned, reducing the imposed effects of birth order and the application of spontaneous human order to behavior is considered as one of the reasons for human intervention in the natural environment and its transformation into a built environment. This rule can be recovered in the architecture of all human settlements and urban planning from the earliest human settlements to modern cities.

\section{Climate, sub-climate, and behavioral patterns}

According to Environmental Encyclopedia (Bortman, 2003), climatic factors are the macro-scale climatic characteristics of a geographical area, while sub-climates are the climatic characteristics of a defined area or space. The characteristics of the sub-climate may be significantly different from the climatic ones depending on how much solar energy is absorbed and how much moisture is retained, or how much wind is directed into or hindered. Considering each urban space as a sub-climate, urban designers try to adjust the climate in the sub-climate so that the characteristics of the sub-climate (urban space) are in the human comfort zone. The desire of people to attend and perform the behavior in this urban space increases by locating urban space in the comfort zone. Bio-climatic or bioclimatic diagrams should be examined for determining the area of human comfort. Temperature and humidity are related to the two main axes of this diagram, along with adding other information such as radiation and wind (Figure 1). As shown, the temperature is the most influential climatic factor in determining the comfort zone. As displayed in Figure 1, only the range between 70 and 75 degrees Fahrenheit (21 to 24 degrees Celsius) is in the comfort zone, while the relative humidity covers a wide range between 20 to $80 \%$ in the comfort zone.

As mentioned, urban designers try to design urban spaces (as sub-climates within the city) in such a way that they are in the climate comfort zone for more times to expand the time of occurrence of urban behaviors. Accordingly, they control, reduce, or direct radiation, wind, and humidity to urban spaces to moderate the ambient temperature.

Radiation and temperature are clearly related. In this way, temperatures lower than the comfort zone are in the comfort zone by increasing radiation (direct and indirect). Accordingly, radiation in the cold period of the year and shading in the warm period of the year can contribute to the comfort of the sub-climate. The relationship between, wind, temperature, and humidity is somewhat more complicated. The breeze will undoubtedly cool the body, either through convection or surface evaporation at temperatures below body temperature. In addition, the wind in the cold period of the year makes the sub-climate more acute, which should be reduced as much as possible. However, at temperatures above the body temperature, surface evaporation causes the body to cool down, while convection causes the body to warm up. Despite this paradox, even at temperatures above body temperature, the wind makes the environment more tolerable due to the drying of the skin's transpiration. After drying the skin, extreme wind at very high 
temperatures causes the temperature to rise and is undesirable. It should be noted that the ability of exercise to evaporate moisture on the skin decreases when the humidity increases, which is especially important in hot and humid climates.

\section{Climatic typology}

In the contemporary era, physical typology, especially in terms of climatic dimensions, has flourished again among architects and urban planners (Moudon, 1994; Hillier, 1996; Kelbaugh, 2002). The science of inventing new combinations in designing urban spaces is consistent with climatic characteristics (Gelerater, 1988). According to Leon Krier, the whole problem of today's spaces was solved in the past. Past spaces represent enduring species which have evolved and stood the test of time, especially about climate (Krier, 1998). Regarding climatic characteristics, the use of species which has passed the test of time is much less dangerous than the invention of new types (Cesar, 1999). In other words, typology seeks to answer the question "How today's climate problems have been answered in similar historical situations?" Thus, the conceptual framework of this paper is such that climatic characteristics, as the most influential aspects of the environment, limit human behavior in terms of time, type, and audience of behavior. On the other hand, the desire for autonomy has led man to design sub-climates to reduce the limiting aspects of the environment. Historical typology is replete with valuable methods in responding to limiting climatic features.

[1] It is claimed that this type of passage of time is specific to the modern era. In this way, these behaviors (such as revolutions or urban movements) are unique and not repetitive.

\section{Methodology}

The present study aims to evaluate the effect of climatic characteristics and the form of urban space on the behavioral patterns of residents. To this aim, a comparative study method was used between behavioral patterns in hot and arid, moderate, and humid climates due to their entirely different climatic characteristics. Behavioral characteristics were harvested and examined using the observation method (timed photography). This method of photography is a random method for capturing urban behaviors at specific intervals and should be considered as a part of visual-behavioral studies. Unlike the research method of this study, the authors used the camera in the urban space by moving the pedestrian (Appleyard, et al., 1964). In two other similar studies, a tracking method suggested by Michelson (1975) aimed to identify the behavioral patterns of individuals in different periods (daily, weekly and monthly), and Winkel and Sasanoff (1966) followed visitors in other spaces. In this study, the movement of people was reflected as a continuous line and the direction of training with an arrow on the plan of spaces (Figure 2).

Despite the innovation, the mentioned research methods also suffer from disadvantages. Most importantly, it was not possible to record various behaviors and compare them in the research. In the research method used in this article, influenced by the conceptual framework section, urban behaviors have been recorded separately for transit-presence behaviors and necessary-optional-social behaviors. In 
this way, black dashed lines indicate transitory and necessary behaviors, circle dots indicate optional behaviors (sitting, eating, studying, etc.), and triangular dots indicate social sub-behaviors[2] (chat, play, etc.) (Figures 6-9). Further, the observer is not observed in timed photography from the bird's point of view, upon which the least amount of interference is created in the behavioral patterns of space users. Thus, this method is suitable for the present study.

Nevertheless, the inability to distinguish between some behaviors like roaming and traffic is considered as the limitations of the present research method. In fact, roaming behavior should be classified as recreational and optional behaviors. However, it is not possible to distinguish it from transit behaviors in this study due to the apparent similarity, and it is mistakenly classified as essential behaviors. However, the distinction between the two behaviors is related to individual motivations. To determine a person's motivation, one must determine the antecedent's conditions or facial expressions and physiological status such as checking blood plasma contents, pupil diameter, etc. (Reev, 2005). Due to the high number of urban space users, the use of questionnaires has been repeatedly suggested in social psychology (Carlsmith et al., 1976). Many motivation theorists, however, have questioned the validity of matching questionnaire responses with the individual reasons (Wicker, 1969). As a result, the proposed alternative research method could be an in-depth interview method. The in-depth interview method also reveals individual motivations more accurately, while they are no less than physiological tests in terms of its time-consuming feature. Accordingly, there may be no choice except to cope with the limitations of the present research method.

There is a similar problem with social behaviors. In the present research method, like other urban researches, it is not even possible to distinguish between different types of social behaviors (spontaneous or planned, continuous or intermittent, repetitive or unique), except for some issues such as depth, honesty, and direct relationship. In this study, human beings are placed side by side, and facing each other is considered equivalent to the performance of social behaviors.

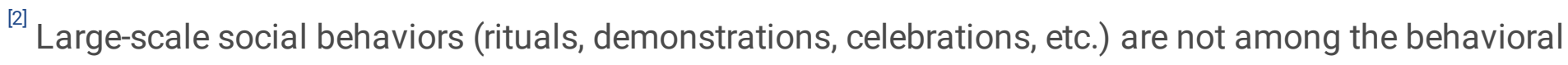
patterns recorded in this study.

\section{Case Studies}

To achieve the objectives mentioned in the previous section, two cities including Amir Chakhmaq Square and Seyed Golsorkh intersection in Yazd as a representative of hot and arid climate and Valiasr and Shohada Square in Fooman as a representative of moderate and humid climate were selected as the case study. The reasons for choosing these two cities are the similarity and comparability of their historical antiquity, significant differences in most climatic indicators in these cities, and the existence of valuable historical contexts in both cities for physical modeling and investigating the effect of climate on how the fabric is formed. The influential climatic characteristics of the selected cities are given in Table 1. 
Table 1

Climatic characteristics affecting urban behaviors in the selected cities (Arseh Architecture and Urban

Planning Consulting Engineers, 2003; Pouya Naghsh Shahr and Bana Consulting Engineers, 2007, Kalantari and Hatami Nejad, 2006; Geographical Organization of the Armed Forces, 1982)

\begin{tabular}{|c|c|c|}
\hline Climatic features & Yazd & Fooman \\
\hline $\begin{array}{l}\text { Geographical } \\
\text { location }\end{array}$ & Desert & Plain \\
\hline $\begin{array}{l}\text { Altitude above the } \\
\text { sea level }\end{array}$ & 1230 meters higher & 15 meters higher \\
\hline Groundwater & Groundwater and aqueducts & River \\
\hline Temperature & Average minimum 8.2 and average maximum 44 & $\begin{array}{l}\text { Average minimum } 3.5 \\
\text { and average maximum } \\
30.3\end{array}$ \\
\hline Precipitation & $140 \mathrm{~mm}$ & $1071.6 \mathrm{~mm}$ \\
\hline Relative humidity & Minimum 17 and maximum 53\% & $\begin{array}{l}\text { Minimum } 74.5 \text { and } \\
\text { maximum } 85.5\end{array}$ \\
\hline Vegetation & Drought-resistant species & $\begin{array}{l}\text { Dense vegetation } \\
\text { (forests and grasslands) }\end{array}$ \\
\hline Wind & $\begin{array}{l}\text { South and southwest wind in summer and North } \\
\text { spring wind in winter and south wind in all seasons }\end{array}$ & West wind prevails \\
\hline $\begin{array}{l}\text { Night and day } \\
\text { temperature } \\
\text { differences }\end{array}$ & In summer, there is a maximum of $20^{\circ} \mathrm{C}$ & $\begin{array}{l}\text { In summer, the } \\
\text { maximum is } 5 \text { degrees } \\
\text { Celsius }\end{array}$ \\
\hline Snow and ice & Only on some days of Bahman & $\begin{array}{l}35 \text { days of frost and } 7 \\
\text { days of snow }\end{array}$ \\
\hline
\end{tabular}

\section{Data Collection Method}

First, the behavioral patterns in four urban spaces in Yazd and Fooman cities were identified and studied using a timed photography method. The photography method was done for ten minutes with a timefrequency of five seconds. This method provides very accurate objective information about behavioral patterns and the effect of climate on them (Figures 3 and 4). Figure 5 displays the knowledge of the blind spots from another angle of view.

Winter harvests are taken place on peak cold days from 10:30 to 10:40 in the morning and 4:30 to 4:40 in the evening, while summer harvests are done on peak heat days from 10:30 to 10:40 in the morning and 8 to $8: 10$ in the afternoon. Obtaining accurate results regarding the role of hot and arid, moderate, and humid climates on behavioral patterns is considered as the main reason for collecting information in two completely different chapters. It was better to record accurate climatic information such as temperature, wind intensity, and humidity while collecting image data, although it was not considered in this study due to its limitations. 
Since the use of urban spaces highly relies on time, and sometimes even the nature of space cannot be compared at two different times of a day or a week and the like (affected by completely other activities). To compare the possibility between spaces and eliminate the chance and effect of unforeseen factors for each period, withdrawals were made on six consecutive days excluding Thursdays and Fridays. This study focused on the average and the result of these six impressions.

Some focused on the effect of urban furniture on behaviors in space (Carmona et al., 2003; Gehl, 1980). To control this variable, the location of urban furniture is also shown in Figures 6-9 in the space plan. It is worth noting that the purpose of urban furniture in this study is not limited to the elements which are commonly designed for this purpose. Still edges of the space, as mentioned by Bentley et al. (1985), the edges of the pond, and any other places that can be used for urban behaviors are also considered urban furniture.

\section{Results}

\section{Results of behavioral patterns in hot and arid climates}

As shown in Figures 6 and 7, the activities of crossing and attending Amir Chakhmaq Square and spending crossing activities at Seyed Golsorkh intersection reach their highest density in the morning in winter and in the evening in summer. In these periods, the ratio of optional and social behaviors to passing behaviors in Amir Chakhmaq Square is more than in the morning in summer and in the evening in winter. In the evening in summer, the optional and social behaviors at the point of elevation of the pond edges, the edges of urban space, and urban furniture have a higher density. A slight decrease in temperature occurs due to an increase in humidity. The same is true for green factors in addition to increasing humidity, radiant trees, green shrubs, and covering elements such as grass for modulating reflection. Further, the center of space has a higher behavioral density due to the more significant benefit of natural ventilation and a reduction in body temperature through the surface evaporation of the skin.

Compared to winter mornings and summer evenings, urban behaviors are less dense both in Amir Chakhmaq Square and at the Seyed Golsorkh intersection in the mornings of the hot season and the evenings of the cold season. In this period, Amir Chakhmaq Square is almost free of static, optional, and social behaviors. Urban behaviors are limited to a set of transitory and necessary behaviors. In the morning of the hot season, the passageways and the Spatio-temporal pattern of presence behaviors are strongly influenced by the shading pattern of the urban space. In this way, the sub-behaviors of presence take place mainly on the southern front of space. However, transit and presence behaviors are denser on the northern front in winter. In this area, escaping from the possible shadow, and the possibility of using the reflection reflected from the city walls is provided along with reducing wind flow. During this period, the presence or absence of urban furniture has little effect on the company of people in the urban space. In fact, only the urban furniture available in the shade in the hot season or under the sun in the cold season is used. On the contrary, the presence at the edges of space is much more fabulous due to the thermal resistance and heat storage of the used materials in addition to radiation and reflection. It is 
worth noting that the amount of wind at the edges of the space is less, which is important in the cold season. Further, the thermal resistance of brick materials at the edges of the space is the same as the thermal resistance of wooden furniture materials. However, brick materials have a higher heat capacity and can transfer heat from day to night and vice versa.

\section{Results of behavioral patterns in moderate and humid climates}

The density of human activities in summer is significantly higher than that of human activities in winter in moderate climates (Figures 8-9).. In fact, the time cycle influencing urban behavior is seasonal rather than circadian in this climate. In other words, the lack of a sharp temperature difference between day and night reduced the impact of this factor on urban scheduling cycles. Instead, the urban space is much closer to comfort due to the high humidity in summer, especially compared to hot and arid climates. In this climate, suitable weather conditions have provided a reasonable ground for the emergence of a wide range of optional and social behaviors such as walking, sitting, seeing, being seen, eating, chatting, and the like. Due to the high humidity, cloudy air, and accordingly the relatively high level of indirect radiation compared to direct radiation, almost all parts of the urban space and the furniture located have been used. However, due to the more significant benefit of the space center from wind and natural ventilation, the density of urban activities is higher, especially optional and social activities in this part of the space. In this climate, even rainfall in the hot season, which is often sporadic, does not cause serious disturbance to urban behavior.

Finally, comparing the two climates indicates that not only the use of urban spaces of moderate and humid climates is more than urban spaces of hot and arid climates, but also the ratio between optional social behaviors or between the sum of social and optional behaviors and necessary behaviors is higher in moderate and humid climates. In other words, temperate and humid urban spaces are more used for non-transit behaviors than hot and arid climatic spaces.

\section{Conclusion}

Based on the results, climate affects urban activities, time cycles of behaviors, and their individual or social nature. In this way, urban behaviors are limited to necessary behaviors, and space is passed in harsh climatic conditions. In contrast, favorable climatic conditions allow the possibility of a wide range of optional and social activities and make the space static. In other words, in the limiting-liberating continuum, the favorable climate acts as the liberating environment, and the bad climate acts as the limiting environment.

On the other hand, the time cycle is different in different climates. For example, urban activities are seasonal in moderate and humid climates, while the time cycle of urban activities is daily in hot and arid climates. On the other hand, the difference between the periods of hot and arid climate (difference between day and night) is much more significant than that of moderate and humid climate (difference between winter and summer). Therefore, there is a more severe difference between the periods of urban 
behaviors in acute climate. Thus, it is predicted that the perception of periods in this climate is more clear and effective.

In addition, the impact of urban behaviors on climatic characteristics is higher in more acute climates, i.e. in hot and arid climates than moderate and humid climates. Thus, more attention should be paid to climatic design in designing urban spaces when the climatic features are harsher and more severe. Further, it should be noted that the requirements of climate design are different in various climates. Thus, satisfying the climatic conditions of temperature, radiation and, reflection is more important given the requirements related to humidity and wind in moderate and humid climates, especially in hot seasons, as well as in hot and arid climates.

Additionally, climatic characteristics are preferred over the area of urban furniture in explaining the location of urban behaviors. In this way, only the urban furniture located in climatic comfort is used. In other words, the place of people's presence and passage rather than determining by urban furniture identifies the location of the sub-space with the whole space (center and periphery, north to south of the space) in such a way that it is effective in occurring urban behaviors in the hot and arid climate in the north-south space. However, the duality of center-around space is essential in moderate and humid climates. In addition, green elements and water play a role in this spatial explanation of behavior.

The study of formal-historical patterns in hot and arid climates indicated that air blinds are suitable as long as the flow does not cause excessive transpiration. It is better to enter the air to transport moisture into the urban space through modeling wind catcher for urban spaces. Further, protection against cold winter winds should be provided so that space is stretched in the direction of summer winds and the direction perpendicular to winter winds. It is essential to consider the heat capacity along with thermal resistance in designing seating areas including the edges of space and urban furniture. Furthermore, regarding historical patterns in hot and arid climates, the space plan should be highlighted, building density should be high, and shading levels should be increased. In this climate, the use of white materials and rough and textured surfaces is common. Glossy surfaces with expansive windows should be avoided. In this climate, the use of green elements including trees, shrubs, coverings, and pendants was expected in enclosed spaces. However, planting cover elements such as grass in this climate is related to the high need for water in the opposite direction of sustainability. Finally, deciduous trees have become common to enjoy the winter sun. Regarding the historical patterns of moderate and humid climates, not only the connection between the enclosing buildings was prevented, but also had slits in the direction of the air blinds deliberately since the shading pattern was less important than the air blinds. Reducing the height, along with using sloping roofs and crawl space, and avoiding the use of shrubs in the center of the space help make the space more ventilated. It is worth noting that the determination of reduced spatial due to discontinuity and reduced wall height can be enhanced by visual design methods such as strengthening the spatial framework.

Finally, the total behavioral density (number of urban behaviors per unit area) in temperate and humid climates is significantly higher than that of hot and dry climates. In other words, environmental 
conditions in temperate and humid climates are more suitable for space use. Perhaps, a part of the extroversion, pluralism, and cultural tolerance of the inhabitants in temperate and humid climates can be attributed to a high frequency of using urban spaces, and the emergence of a broader range of urban behaviors by other citizens. In other words, a temperate climate is considered as a good ground for a culture of soft relativism and inclusiveness. On the other hand, harsh conditions of hot and dry climates not only impose more indoor hours on residents, but also allow for a much more limited range of urban behaviors. Accordingly, a part of the introversion of the people of this geographical area may be attributed to the behavioral patterns imposed by the climate, or the vital need for social normative conformity in this climate can be justified through the limited range of possible behaviors in urban spaces. It is worth noting Iran has cold and mountainous, as well as hot and humid climates. Other studies in the above-mentioned climates with the research method used in this article can evaluate the results of this research in the mentioned climates. Future studies can focus on finding a way to distinguish between forced and voluntary behaviors and different types of social interactions accurately, along with collecting visual data and climate information of the selected locally-registered urban spaces.

\section{Declarations}

Hereby, I Sara Ahmadi consciously assure that for the manuscript "The effect of sub-climatic characteristics on urban behavior patterns based on two case studies: Yazd (hot and arid climate) and Fooman (moderate and humid climate) urban spaces" the following is fulfilled:

1) This material is the authors' own original work, which has not been previously published elsewhere.

2) There are no conflicts of interest to declare.

3) The paper reflects the authors' own research and analysis in a truthful and complete manner.

4) The paper properly credits the meaningful contributions of co-authors and co-researchers.

5) The results are appropriately placed in the context of prior and existing research.

6) All sources used are properly disclosed (correct citation).

7) All authors have been personally and actively involved in substantial work leading to the paper, and will take public responsibility for its content.

\section{References}

Alfonzo, M., Boarnet, M. G., Day, K., Mcmillan, T., \& Anderson, C. L. (2008). The relationship of neighbourhood built environment features and adult parents' walking. Journal of Urban Design, 13(1), 2951. https://doi.org/10.1080/13574800701803456 
Askarizad, R., Safari, H. (2020). The influence of social interactions on the behavioral patterns of the people in urban spaces (case study: The pedestrian zone of Rasht Municipality Square, Iran). Cities, 101, 1-16. https://doi.org/10.1016/j.cities.2020.102687

Becker, F. D., \& Steele, F. (1995). Workplace by design: Mapping the high-performance workscape: JosseyBass. https://psycnet.apa.org/record/1995-97723-000

Bereitschaft, B. (2017). Equity in microscale urban design and walkability: A photographic survey of six Pittsburgh streetscapes. Sustainability, 9(7), 1233. https://doi.org/10.3390/su9071233

Boakye-Dankwa, E., Nathan, A., Barnett, A., Busija, L., Lee, R. S., Pachana, N., . . Cerin, E. (2019). Walking behaviour and patterns of perceived access to neighbourhood destinations in older adults from a lowdensity (Brisbane, Australia) and an ultra-dense city (Hong Kong, China). Cities, 84, 2333. https://doi.org/10.1016/j.cities.2018.07.002

Bortman, M. (2003). Environmental encyclopedia: Gale. https://www.elibrary.ru/item.asp?id=19798270

Carmona, M., Heath, T., Oc, T., \& Tiesdell, S. (2003). Urban spaces-public places: The dimensions of urban design. In: Oxford: Architectural Press.

Castells, M. (1977). The Urban Question (London, Arnold). Forester, J.(1989) Planning in the Face of Power.

Castells, M. (1983). The city and the grassroots: A cross-cultural theory of urban social movements: Univ of California Press.

Cervero, R., Sarmiento, O. L., Jacoby, E., Gomez, L. F., \& Neiman, A. (2009). Influences of built environments on walking and cycling: lessons from Bogotá. International journal of sustainable transportation, 3(4), 203-226. https://doi.org/10.1080/15568310802178314

Cowan, R., \& Rogers, L. (2005). The dictionary of urbanism (Vol. 67): Streetwise press Tisbury.

De Greef, K., Van Dyck, D., Deforche, B., \& De Bourdeaudhuij, I. (2011). Physical environmental correlates of self-reported and objectively assessed physical activity in Belgian type 2 diabetes patients. Health \& social care in the community, 19(2), 178-188. https://doi.org/10.1111/j.1365-2524.2010.00958.x

Deci, E. L., \& Ryan, R. M. (1991). A motivational approach to self: Integration in personality. https://psycnet.apa.org/record/1991-98255-005

Direito, A., Walsh, D., Hinbarji, M., Albatal, R., Tooley, M., Whittaker, R., \& Maddison, R. (2018). Using the intervention mapping and behavioral intervention technology frameworks: development of an mHealth intervention for physical activity and sedentary behavior change. Health Education \& Behavior, 45(3), 331348. https://doi.org/10.1177/1090198117742438 
Fleming, R., Baum, A., \& Singer, J. E. (1985). Social support and the physical environment. https://psycnet.apa.org/record/1985-97489-016

Frank, L. D., Sallis, J. F., Conway, T. L., Chapman, J. E., Saelens, B. E., \& Bachman, W. (2006). Many pathways from land use to health: associations between neighborhood walkability and active transportation, body mass index, and air quality. Journal of the American planning Association, 72(1), 7587. https://doi.org/10.1080/01944360608976725

Gans, H. (1962). The Urban Villagers: Group and Class in the Life of Italian-Americans. In: New York: Free Press.

Gehl, J. (1980). The residential street environment. Built Environment (1978-), 51-61. https://www.jstor.org/stable/23286085

Gehl, J., \& Gemzøe, L. (1999). Public Spaces Public Life-Copenhagen 1996. Copenhagen. In: The Danish Architectural Press and The Royal Danish Academy of Fine Arts ....

Habermas, J., \& Habermas, J. (1971). Toward a rational society: Student protest, science, and politics (Vol. 404): Beacon Press.

Hahm, Y., Yoon, H., Choi, Y. (2019). The effect of built environments on the walking and shopping behaviors of pedestrians; A study with GPS experiment in Sinchon retail district in Seoul, South Korea. Cities, 89, 1-13. https://doi.org/10.1016/j.cities.2019.01.020

Halbwachs, M. (2020). On collective memory: University of Chicago Press.

Hamin, E. M., \& Gurran, N. (2009). Urban form and climate change: Balancing adaptation and mitigation in the US and Australia. Habitat international, 33(3), 238-

245. https://doi.org/10.1016/j.habitatint.2008.10.005

Harvey, D. (2000). Possible Urban Worlds. The Fourth Megacities Lecture. Amersfoort, The Netherlands: Twynstra Gudde Management Consultants.

Jacobs, J. (1961). The Death and Life of Great American Cities, . New York: Random House.

Kelly, C. M., Schootman, M., Baker, E. A., Barnidge, E. K., \& Lemes, A. (2007). The association of sidewalk walkability and physical disorder with area-level race and poverty. Journal of Epidemiology \& Community Health, 61(11), 978-983. http://dx.doi.org/10.1136/jech.2006.054775

Koo, B. W., Guhathakurta, S., \& Botchwey, N. (2021). How are Neighborhood and Street-Level Walkability Factors Associated with Walking Behaviors? A Big Data Approach Using Street View Images.

Environment and Behavior. https://doi.org/10.1177/00139165211014609 
Koohsari, M. J., Sugiyama, T., Shibata, A., Ishii, K., Hanibuchi, T., Liao, Y., Owen, N., Oka, K. (2018). Walk Score ${ }^{\circledR}$ and Japanese adults' physically-active and sedentary behaviors. Cities, 74, 151155. https://doi.org/10.1016/j.cities.2017.11.016

Kwon, H. R., \& Silva, E. A. (2020). Mapping the landscape of behavioral theories: Systematic literature review. Journal of Planning Literature, 35(2), 161-179. https://doi.org/10.1177/00139165211014609

Leventhal, T., \& Brooks-Gunn, J. (2003). Moving to opportunity: an experimental study of neighborhood effects on mental health. American journal of public health, 93(9), 1576-

1582. https://doi.org/10.2105/AJPH.93.9.1576

Li, F., Harmer, P., Cardinal, B. J., \& Vongjaturapat, N. (2009). Built environment and changes in blood pressure in middle aged and older adults. Preventive medicine, 48(3), 237-

241. https://doi.org/10.1016/j.ypmed.2009.01.005

Lynch, K. (1972). What time is this place?: Mit Press.

McCormack, G. R., Koohsari, M. J., Turley, L., Nakaya, T., Shibata, A., Ishii, K., . . Oka, K. (2019). Evidence for urban design and public health policy and practice: space syntax metrics and neighborhood walking. Health \& Place, 102277. https://doi.org/10.1016/j.healthplace.2019.102277

Moos, R. H. (1973). Conceptualizations of human environments. American psychologist, 28(8), 652. https://doi.org/10.1037/h0035722

Olgyay, V. (2015). Design with climate: bioclimatic approach to architectural regionalism-new and expanded edition: Princeton university press.

Peponis, J., Wineman, J., Bechtel, R., \& Churchman, A. (2002). Handbook of environmental psychology. In: New York, NY: Wiley.

Philo, C. (2009). International encyclopedia of human geography. https://doi.org/10.1515/9783110819052

Rapoport, A. (1976). The mutual interaction of people and their built environment: A cross-cultural perspective: De Gruyter Mouton.

Rapoport, A. (2013). History and precedent in environmental design: Springer Science \& Business Media.

Rapoport, A. (2016). Human aspects of urban form: towards a man-environment approach to urban form and design: Elsevier.

Reeve, J. (2014). Understanding motivation and emotion: John Wiley \& Sons.

Reeve, J., Deci, E. L., \& Ryan, R. M. (2004). Self-determination theory: A dialectical framework for understanding socio-cultural influences on student motivation. Big theories revisited, 4, 31-60. 
Rohrer, J., Pierce, J., \& Denison, A. (2004). Walkability and self-rated health in primary care patients. BMC Family Practice, 5(1), 1-7. https://doi.org/10.1186/1471-2296-5-29

Ryan, R. M., \& Deci, E. L. (2000). The darker and brighter sides of human existence: Basic psychological needs as a unifying concept. Psychological inquiry, 11(4), 319-

338. https://doi.org/10.1207/S15327965PLI1104_03

Simmel, G. (2012). The metropolis and mental life: Routledge.

Smith, K. R., Brown, B. B., Yamada, I., Kowaleski-Jones, L., Zick, C. D., \& Fan, J. X. (2008). Walkability and body mass index: density, design, and new diversity measures. American journal of preventive medicine, 35(3), 237-244. https://doi.org/10.1016/j.amepre.2008.05.028

Soja, E. W. (1971). The Political Organization of Space, Resource Paper No. 8.

Soja, E. (2010). Globalization and Community: Seeking Spatial Justice. Minneapolis, US. In: University of Minnesota Press. Retrieved from http://www. ebrary. com.

Sun, X., Wang, L., Wang, F., Soltani, S. (2020). Behaviors of seniors and impact of spatial form in smallscale public spaces in Chinese old city zones. Cities, 107, 1-

9. https://doi.org/10.1016/j.cities.2020.102894

Sundstrom, E., Sundstrom, M. G., \& Eric, S. (1986). Work places: The psychology of the physical environment in offices and factories: CUP Archive.

Taylor, L. M., Leslie, E., Plotnikoff, R. C., Owen, N., \& Spence, J. C. (2008). Associations of perceived community environmental attributes with walking in a population-based sample of adults with type 2 diabetes. Annals of behavioral medicine, 35(2), 170-178. https://doi.org/10.1007/s12160-008-9021-3

Tonkiss, F. (2005). Space, the city and social theory: Social relations and urban forms: Polity.

Whyte, W. H. (1980). The social life of small urban spaces.

Wirth, L. (1998). The ghetto (Vol. 7): Transaction Publishers.

\section{Figures}




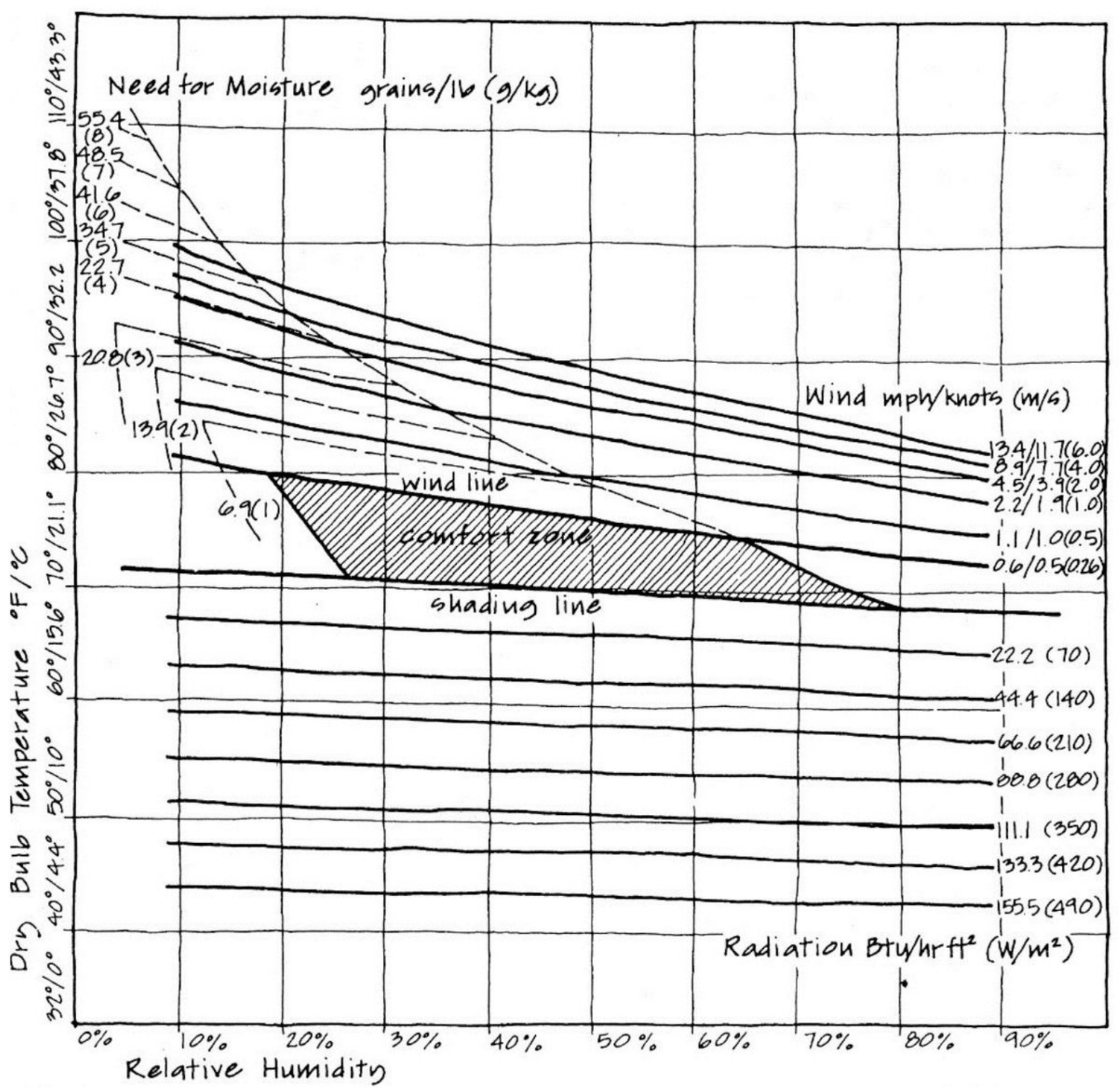

Figure 1

Bioclimatic table (Increasing the power of radiation at lower temperatures in the comfort zone and increasing the intensity of the wind puts the higher temperatures in the comfort zone in the range of climatic comfort. Further, the effect of wind on tolerating high temperatures increases when the air dries while decreasing humidity) (Olgyay, 2015) 


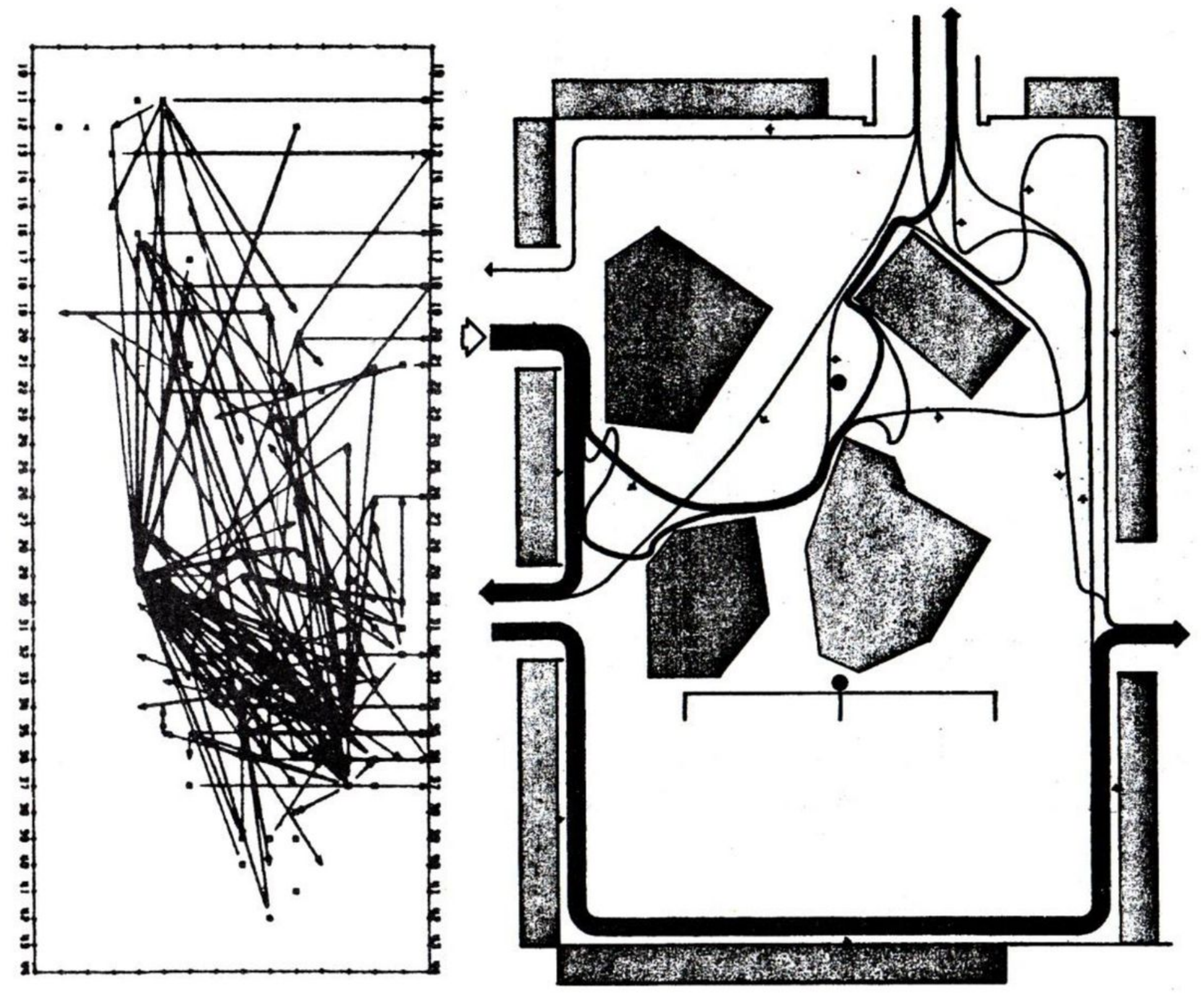

Figure 2

The movement pattern of people in space: Michelson's research (right) and Winkel and Sasanoff's research (left) 


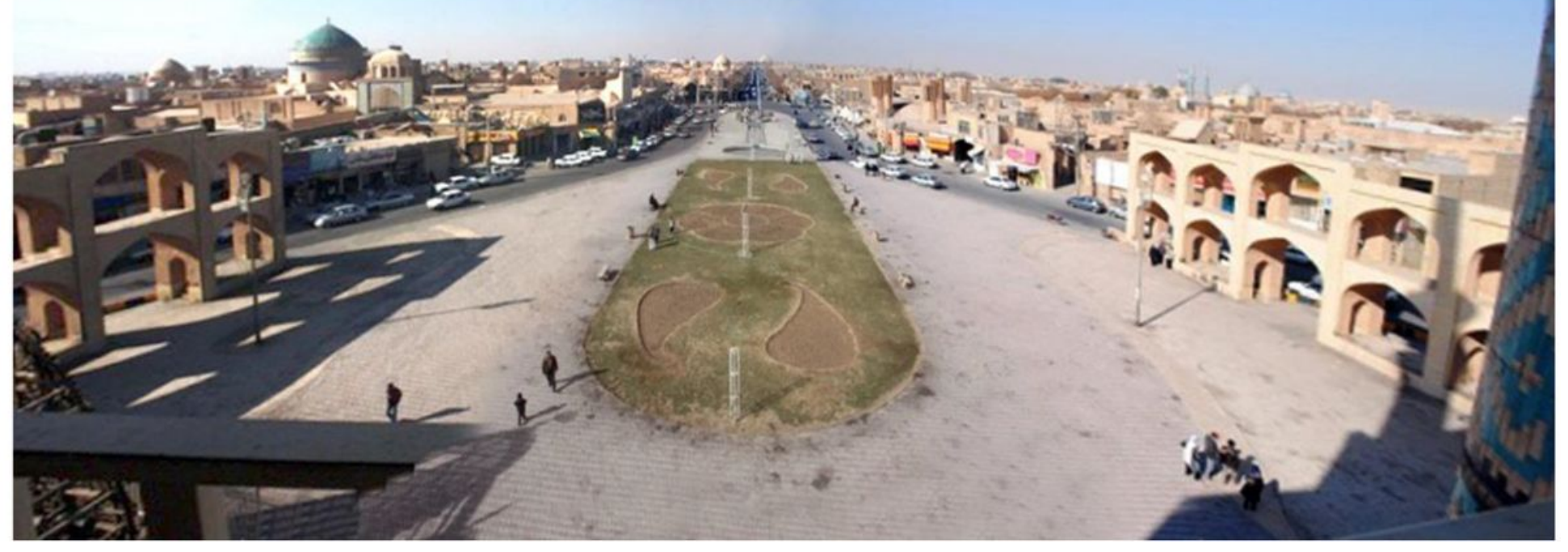

\section{Figure 3}

Sample photograph of Amir Chakhmaq Square in Yazd

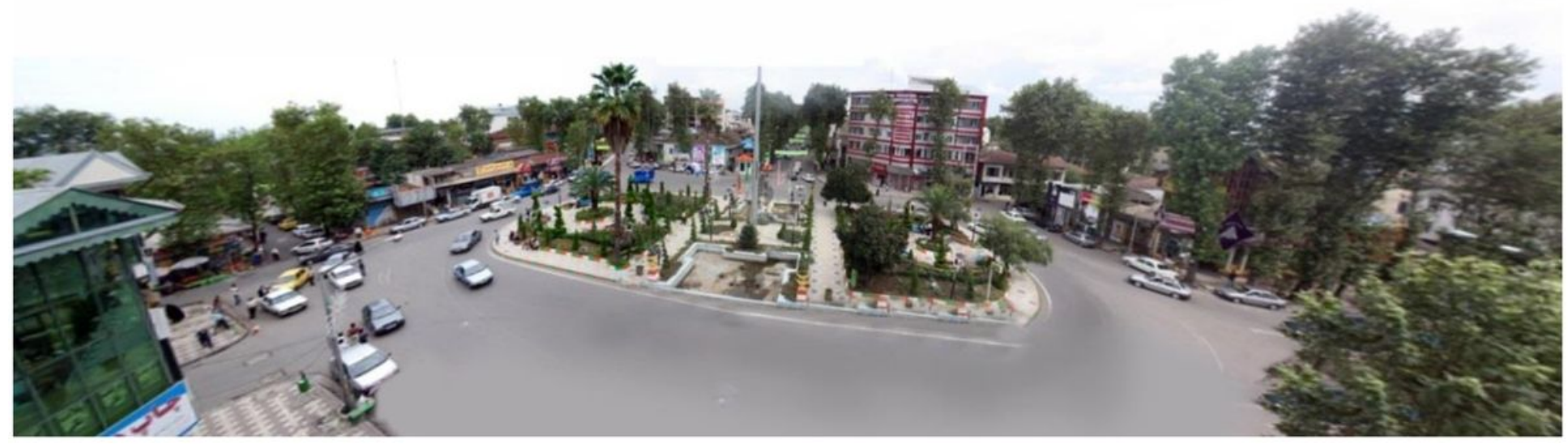

\section{Figure 4}

Sample photograph of Valiasr Square in Fooman

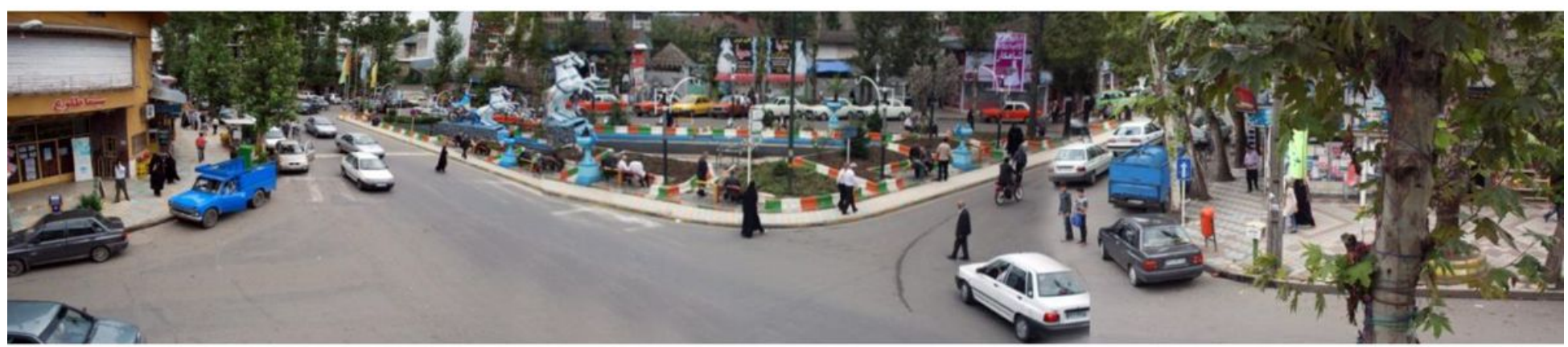

\section{Figure 5}

Re-imaging to complete the information of the blind part in bird vision photography 

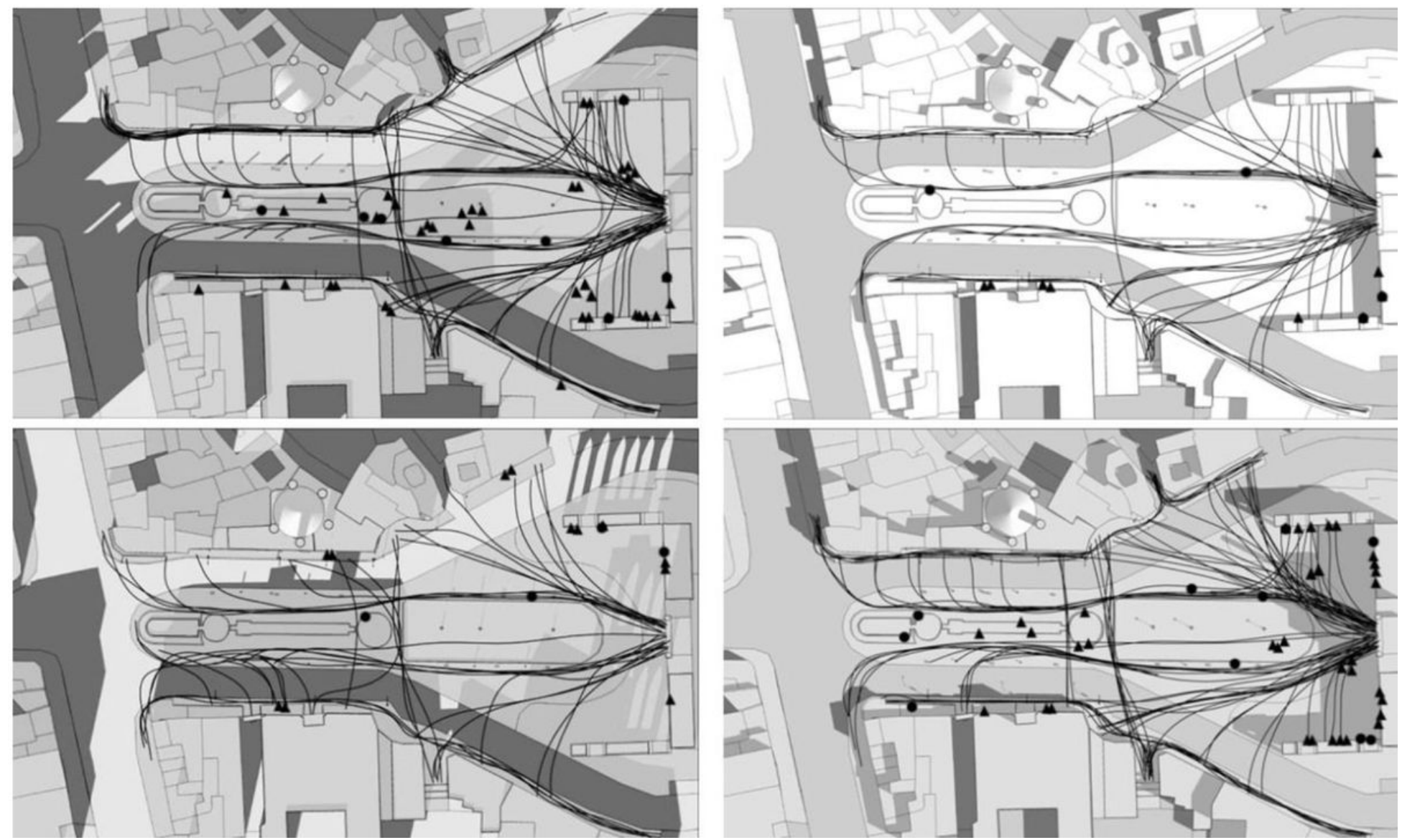

Figure 6

User's behavioral patterns of Amir Chakhmaq Square in Yazd in the morning (right), evening (left), summer (up), and winter (down) 

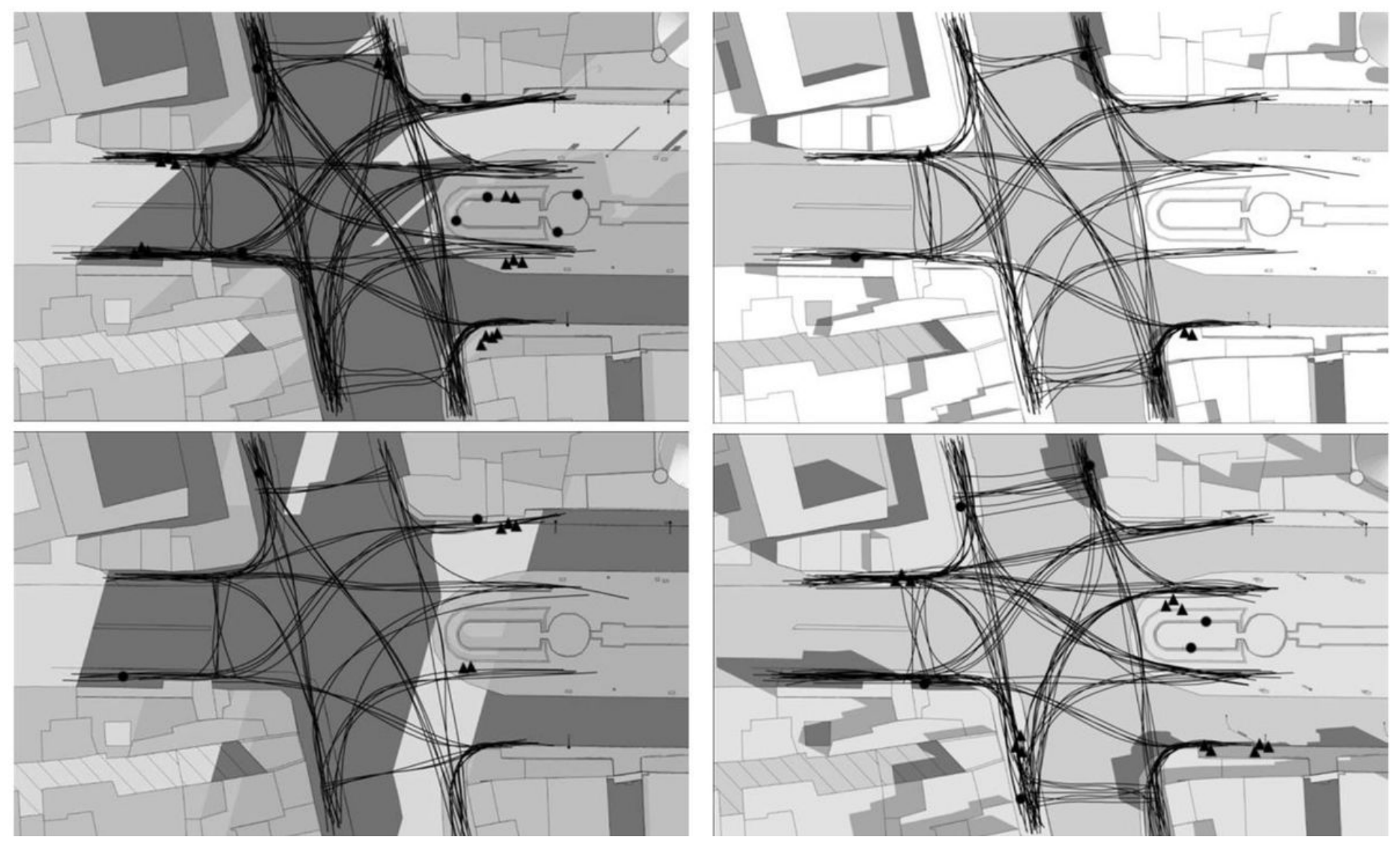

Figure 7

User's behavioral patterns of Seyed Golsorkh intersection in Yazd in the morning (right), evening (left), summer (up), and winter (down)
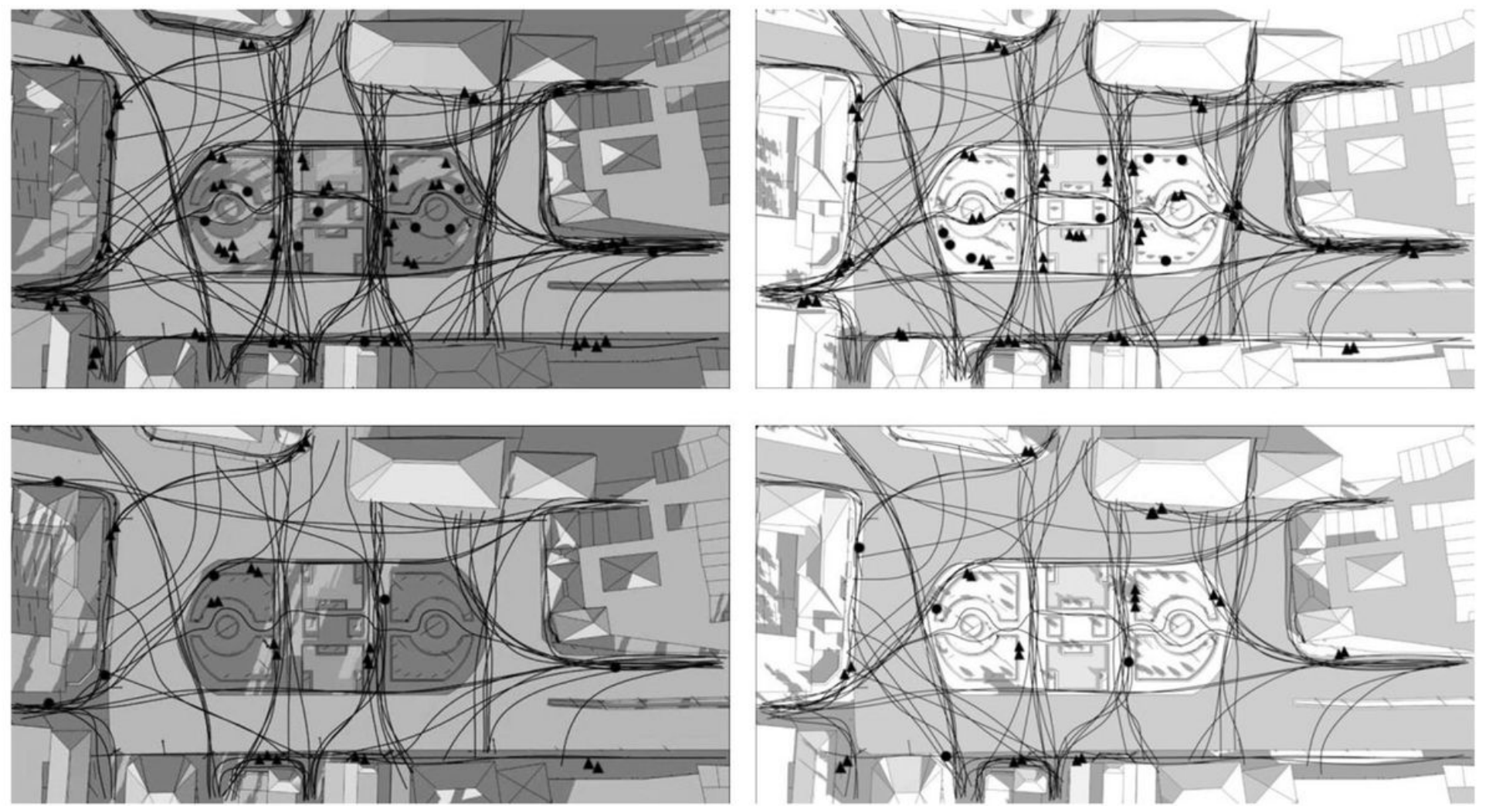


\section{Figure 8}

User's behavioral patterns of Valiasr Square in Fooman in the morning (right), evening (left), summer (up), and winter (down)
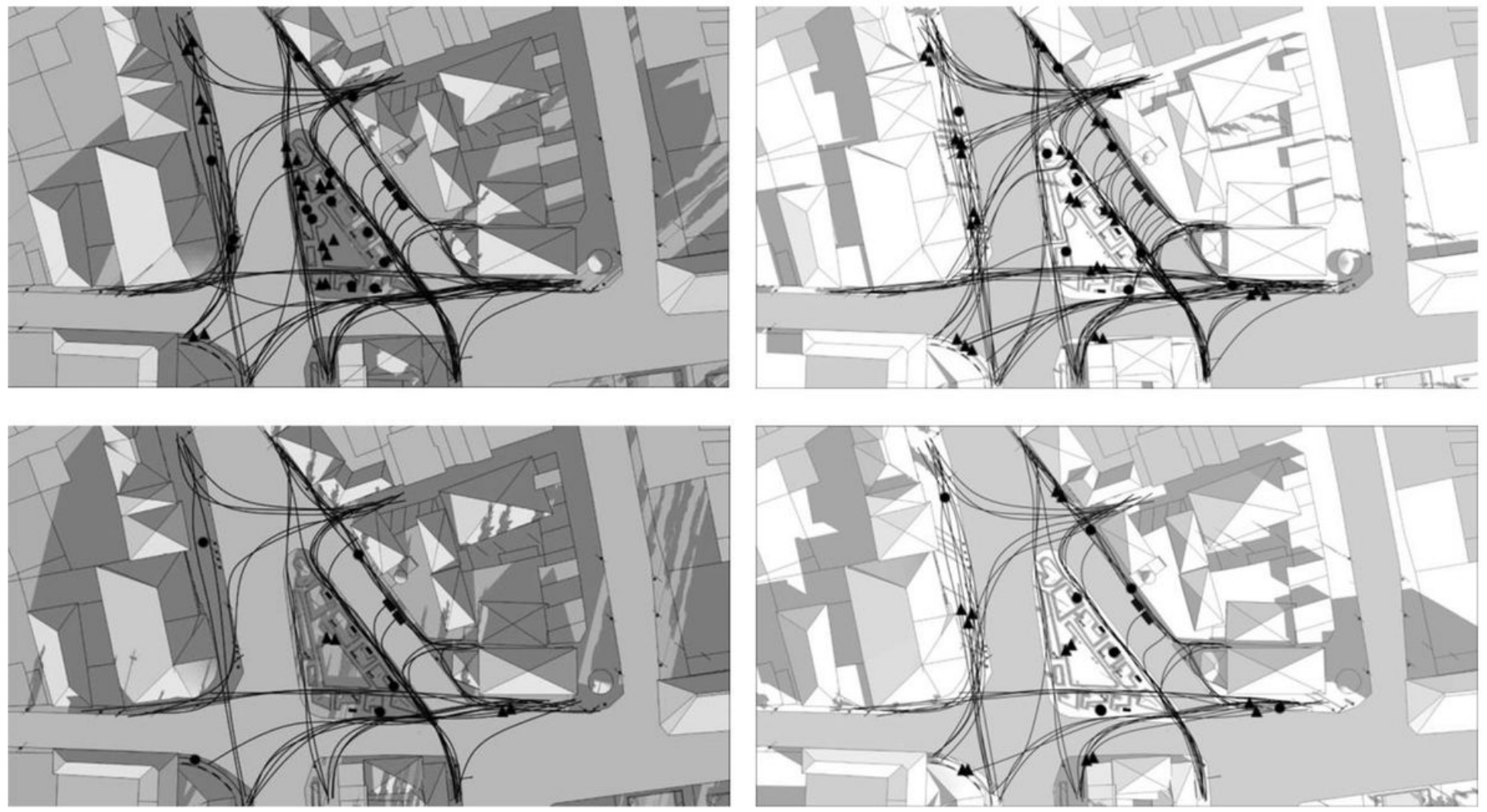

\section{Figure 9}

User's behavioral patterns of Shohada Square in Fooman in the morning (right), evening (left), summer (up), and winter (down) 